tunics. This is true, also, of other non-traumatic forms of detachment. Exudation, as a causal agent, is derived from the choroid, or occurs as a serous effusion from the retina, and is the direct cause of detachment in the retinitis of albuminuria, etc. When present in idiopathic detachment such exudation plays a purely secondary part.

No real progress in the treatment of this affection, so serious and hitherto so intractable, can be hoped for unless a genuine attempt is made to determine the pathogenesis in every case.

While it is true that in many instances this is extremely difficult, it is equally true that not infrequently a thorough clinical examination affords a clue to the cause of the detachment and a guide to the measures to be advised.

\title{
Ophthalmia Neonatorum
}

The discussion on the prevention and treatment of ophthalmia neonatorum, which took place at the recent congress of the Ophthalmological Society of the United Kingdom, has brought into prominence once again the greatest cause of preventible blindness: Much has been done in this country to mitigate the scourge, as witness the notification of the disease, the registration of midwives, the provision of health visitors, and last, but not least, the opening in some cities, as Manchester, Liverpool, Glasgow, and London, of hospitals for the reception of affected babies and their mothers. But more is called for, and that can only be met by the adoption of prophylaxis in all cases of childbirth. The precise means adopted may differ, nor does that matter, always provided they are efficient. In the upper classes, where gonorrhoea is relatively rare, some simple means, such as that suggested by Samuel Hague in 1879 (Brit. Med. Jour., June 21, 1879, p. 959), who wiped away every trace of moisture from the baby's eyelids the moment the head was born, together with the careful washing of the baby's hands and arms, would probably suffice. In institutions where women are delivered at the cost of the community, when gonorrhoea is present in the mother, when there is a history of inflamed eyes in former babies, and in the lower classes generally, probably the best preventive is by the instillation into each eye of a single drop of 1 per cent. solution of silver nitrate. Credé, it will be recalled, employed 2 per cent. silver nitrate, and the efficacy of his method has furnished its proofs long ago. At the same time the plan is not altogether free from objections. Even when most carefully applied, it does not prevent all cases of ophthalmia. It is clearly powerless to prevent ante partum or post partum infection. Its use is nearly always followed by reaction on the part of the conjunctiva, as shown by 
discharge and redness. Certain figures show that the 1 per cent. solution is fully as protective as the 2 per cent. solution. For example, in 76,452 infants treated by Crede's plan the percentage of ophthalmia was $0 \cdot 703$, while in 18,393 infants whose eyes were were treated with a 1 per cent. solution the percentage of ophthalmia was 0.628 . In conclusion, the fact must be insisted upon that whatever method of prophylaxis be employed, whether aseptic or antiseptic, precautions against infection of the baby's eyes must be maintained throughout the whole period of lying-in.

\section{ABSTRACTS}

\section{I.-LATENT NYSTAGMUS}

van der Hoeve, J. (Groningen, Holland).-Latent nystagmus. Arch. d'Ophtal, Dec., I9I7, and Nederl. Tijdschrift voor Geneeskunde, 1918, I, No. 12, p. 730.

van der Hoeve records eight cases of latent nystagmus. With both eyes open, the eyes were steady, but on covering one eye horizontal nystagmus appeared instantaneously, which diminished the vision to respectively $1 / 7,1 / 5,1 / 5,1 / 3,2 / 7,1 / 2$, and $2 / 3$ of the vision with both eyes. When both eyes were closed, they were steady; if one eye was closed and the open eye was fixed with fingers or a forceps, so that no movement was possible, the vision was as good as with both eyes. The movements are, therefore, the cause of the diminished vision.

Four of the cases showed strabismus, one latent strabismus, the other three had no strabismus at all; the field of fixation was normal in all cases. Five patients had chorio-retinitis, only one had quite normal eyes. Ears and static organs were exactly tested. Labyrinth diseases, syphilis, or nerve diseases were not found in considerable amount.

Wehrli's explication of latent nystagmus, as caused by insufficiency of the eye muscles, is rejected for these cases. All patients showed spring nystagmus with the fast phase to the side of the fixing eye.

van der Hoeve agrees with Fromaget that the tonic centre of the associated eye movements is the final aim of numerous centripetal impressions, auditory, optical, psychical, general, etc., and that all these excitations give a tonus in that centre which governs the balance of the eye movements. In normal individuals the balance is so stable that one or other of these excitations can be diminished 